\title{
Collaborative Story Craft: A Tool for Building Narratives in Organisational Change
}

\begin{abstract}
In this chapter, we describe Collaborative Story Craft (CSC) as a tool for building narratives during organisational change. The chapter is divided into four parts: externalisation of stories, mirror materials, a workshop, and report. The workshop is structured around metaphoric fields to engage the practitioners. These fields are "Nurturing the Roots," "Occupational Well-being as a holistic story," and "Metaphorical Tourism." The metaphoric fields can be introduced on the same workshop day or spread over separate occasions, depending on the time and the size of the group.
\end{abstract}

Keywords Collaboration $\bullet$ Sensemaking $\bullet$ Craft $\bullet$ Intervention methodology $\bullet$ Occupational well-being $\bullet$ Organisational change

\section{Collaborative Story Craft in Practice}

A work as craft mindset through Collaborative Storytelling provides an opportunity to reflect and critically question current ways of working. Throughout history, craft has emerged as an alternative to mass industrial production and consumption based on profit (Luckman 2015). Craft comes from a desire for authenticity to give meaning to embodied, social experiences (Fine 2003) by drawing from past traditions and shared understanding of social and work life (Jasanoff 2015).

(C) The Author(s) 2022

T. Cleland Silva, P. de Tarso Fonseca Silva, Making Sense of Work

Through Collaborative Storytelling, https://doi.org/10.1007/978-3-030-89446-7_5 
When introducing Collaborative Story Craft (CSC) intervention to a workplace, Story Mediators simplify the description of the process by bringing the participants into a craft mindset, leading them into a metaphoric field with an invitation: "let's craft a story together." We also try to avoid the word "intervention" when conducting Collaborative Story Craft, in order to be in line with the choice of words from the "invitation" and to support the craft mindset.

The members of the organisation, taking part in the Collaborative Storytelling Activity through the Collaborative Story Craft intervention are primarily referred to as "storytellers."

As a supporting tool in processes of organisational change, CSC can lead to multiple parallel outcomes. It all depends on the intention established by the decision makers and how Collaborative Storytelling Activity relates to the main activity system of the organisation. For example, the object of work of the organisation's main activity may or may not be aligned with the object of work of different departments or even the object of work within a temporary project, such as a strategy for organisational change.

Although the object of an activity (or multiple intersecting activities) within an organisation can be complex, Collaborative Storytelling as its own activity has a clear object: to find a common story and/or to establish a compromising zone for collaboration towards a common purpose. In many ways, the process of finding a common story in a community of practice may reveal how individuals interpret what they do together and how they relate to one another (exchanging experiences, learning, and collaborating).

In its original form, CSC is conducted in four phases (Cleland Silva and Fonseca Silva 2019). With the first and second phases, each storyteller takes part in an individual session with a Story Mediator. The third phase consists of the workshop with one or more Story Mediators and members of the organisation as storytellers. The number of Story Mediators for a CSC intervention is a minimum of two throughout the process, while the number of storytellers may vary depending on the size and needs of the organisation. The recommended (maximum) number of storytellers in a workshop is 20 . 


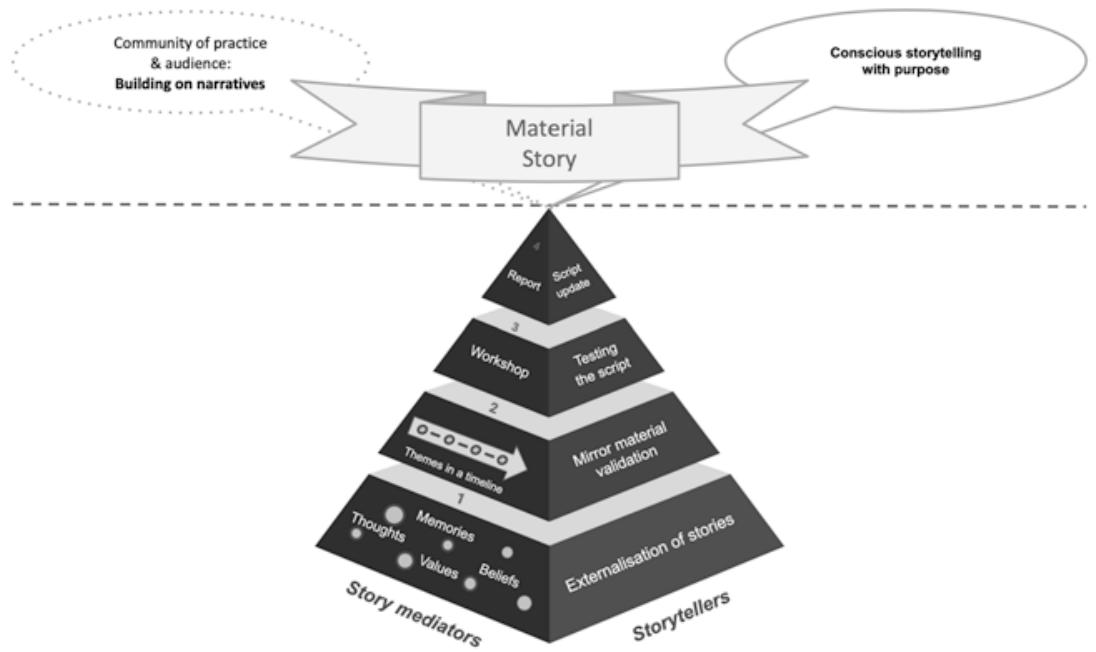

Fig. 5.1 Collaborative Storytelling Activity with the intervention tool Collaborative Story Craft

The sensemaking process of the CSC phases differs between Story Mediators and storytellers. The version of CSC in Fig. 5.1 represents what each role (Story Mediator or storyteller) should expect prior to the starting of the intervention.

This two-dimensional model aims to represent the storytellers' perspectives as well as the Story Mediators' perspective of the same Collaborative Storytelling process. This version was built on the original, (one dimensional) Collaborative Story Craft model (Cleland Silva and Fonseca Silva 2019, p. 10).

The horizontal line divides the phases of the process below as what we perceive as collaborative "story craft." It represents what needs to be explored, understood, selected, agreed upon, and officialised in order to represent the collective. Above the line is anything that is commonly perceived as "storytelling" or material story, such as what is intended to be publicly told, promoted, or sold.

After the CSC intervention, the material story is supported by the updated script, which, on an individual level, may lead to conscious storytelling with purpose. On an organisational level, the updated script builds on the community of practice's narrative and its audience. 
Although intersecting, the focus of each individual during the process is influenced by the responsibilities of each role (not only during the development of CSC but also within the organisation). In addition, the various perspectives of the CSC method can range depending on whether or how the individual had been exposed to the method before. In summary, the two perspectives represented in this model focus on each role (storyteller and Story Mediator) associated with their responsibilities or commitments in the process of change through the activity of Collaborative Storytelling.

Story Mediators should guide the storytellers throughout the process, and this also makes Story Mediators familiar with the overall storyteller's perspective (not the specific individual experience but as it is presented in Fig. 5.1). In other words, the perspective of the Story Mediator starts from his/her sense of responsibility (also as a researcher, interventionist, facilitator, and consultant), and it requires focus on a particular dimension (or perspective) in the Collaborative Storytelling process. Story Mediators have to (1) understand how CSC can be used as an intervention tool, (2) lead the way for the storytellers, so that they can make sense and contribute to the process, and $(3)$ consider the storytellers as their own audience ${ }^{1}$ for the final report.

At the same time, the storyteller's perspective does not prevent him/ her from being exposed to the Story Mediator's perspective. However, engaging in each phase of the CSC process

does not require that the storyteller follows how the Story Mediator conducts his/her responsibilities. This freedom enables the storyteller to prioritise his/her own story in order to relate it to the organisation and later make connections with the story of other organisational members.

\section{Introducing Collaborative Story Craft}

TO THE WORKPLACE

Once the Collaborative Storytelling Activity officially initiates, CSC intervention is introduced to the workplace through a circular model, ${ }^{2}$ and it correlates with the undergoing organisational change. The circular model represents a cycle in the organisation's story as a whole. In order to make sense of the current cycle, everyone involved (Story Mediators and storytellers) will go through a four-step process that can lead to a fifth step (material story) or a brand new cycle of CSC with renewed ideas and an updated purpose (Fig. 5.2). 


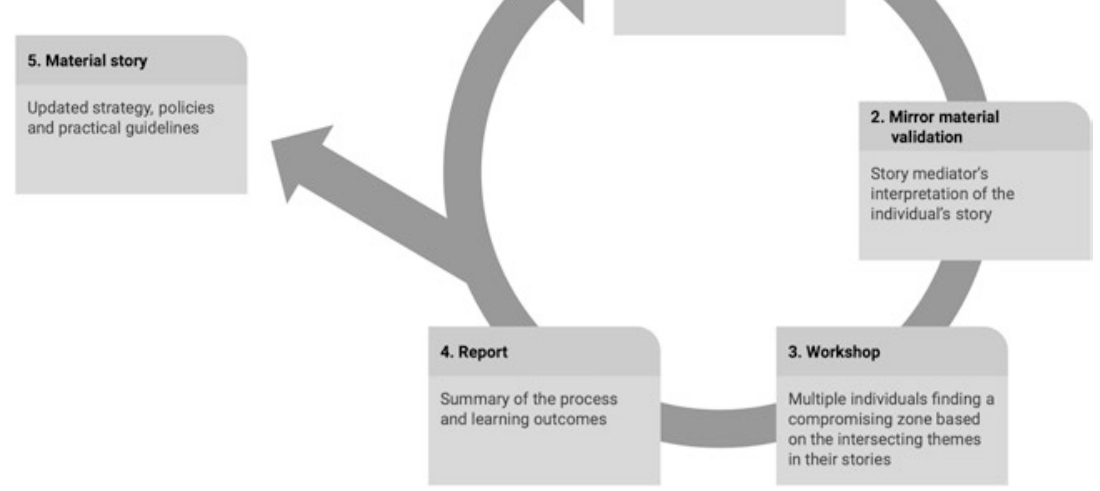

Fig. 5.2 Cyclical model of Collaborative Storytelling during organisational change with the intervention method of Collaborative Story Craft

\section{Part One}

\section{Externalising Stories: Identifying Themes and Metaphors}

Having a one-on-one session makes it easier to enable a safe environment to establish trust. It also initiates a story sharing mindset between the Story Mediator and the storyteller. For that reason, when externalising stories, there should be only one Story Mediator conducting the session, in order to diminish the amount of unnecessary stimulus or distractions.

For the storytellers, this phase means letting the ideas, memories, and opinions flow, orally. The elements of their narratives do not need to be structured in a certain way nor do they need to make complete sense. It is common that storytellers express their surprise regarding what they just told, not because it was anything new or too personal, but because it revealed something insightful that they did not anticipate before listening to themselves speaking aloud.

Each Story Mediator is the expert of his/her own craft, so he or she should select or prepare a set of lines to inform and reassure the storyteller about the process as a whole. The following lines came from our previous publication (Cleland Silva and Fonseca Silva 2019, p. 10) and they exemplify 
what we have used in our practice to explain and guide the storytellers at the first individual session of the CSC intervention (externalisation of stories).

As Story Mediators, we are responsible for taking notes, not to register

- You will be able to craft a script for your story based on what you want others in the organisation to know about you.

- Your story is connected with the collective story and your ideas contribute to future strategies.

- I have no expectation on what you should tell.

- There is no right or wrong way to tell your story.

- At this point, it is normal for the story to be messy.

- I am here to listen and take notes so that we can help you to structure your story.

- Your story is yours to share and, as a storyteller, you can choose what you would like to share to others.

- We will not share your story without your consent.

- The workshop is the context in which you will be able to share your story.

- The themes in your story that connect with other participants' stories may influence the topics we address at the workshop. However, the identities of the storytellers whose themes were selected will not be revealed.

- In the next session, we can reinterpret the story together and select what is relevant to your story.

everything that was shared (literally), but instead to capture moments in the narrative that, we felt, represented something important. In our practice, we identify recurring themes, metaphors, and the identification of a shift in the storyteller's emotions as important moments to take note.

In other words, Story Mediators hold space for the storytellers. They bear witness to the manifestation of the stories and the sensemaking process. It is a challenge to retain as much information as possible while showing genuine interest. However, this is also a sign that although Story Mediation can be taught, it does require a genuine interest in storytelling work through a craft mindset. 
Considering that we all are storytellers (Cleland Silva and Fonseca Silva 2021), after the first session, Story Mediators also need to tell about the stories they have encountered as a way to make sense of their notes. This includes, especially, the interpretation they have afforded to the metaphors and the relations among the recurring themes. Therefore, after the individual session with the storyteller (of the organisation), the primary Story Mediator tells another Story Mediator about his/her impressions of the story that he/she received. In our practice, this storytelling activity, from one Story Mediator to another, is called "offloading."

Although the Cambridge dictionary's meaning of offloading refers to getting rid of something that you do not want by giving it to someone else, sharing the experience with another Story Mediator is not intended to get rid of the story or transfer the responsibility to another person. Instead, we aim to diminish our bias and the limits of our socially constructed lens. By having a second opinion and the opportunity to listen to our own thoughts aloud, both Story Mediators (primary and supporting Story Mediator) exchange ideas as to how the content for the potential "script" could be organised and structured. This potential "script" for the storyteller is also called mirror material, and it can be structured in a word document, PowerPoint slide, or any other way that can be later shared with the storyteller. The structure of the developing "script" takes into account the main themes or metaphors of the narrative as "chapters," which are placed in a chronological order.

\section{PART Two}

\section{Structuring Themes and Validating Stories}

This is the second (and last) individual session in a cycle of the CSC intervention. For the storytellers, this phase means that they get to listen to their own story in the Story Mediator's voice. The storytellers are usually very intrigued and curious about what the story has become from what they shared in the previous session. Without knowing, their emotions become more expressive, and it shows in the way they communicate while validating, correcting, or complementing the Story Mediator's interpretation of their story.

In this session, the Story Mediator also embodies a storyteller's role without losing sight of their own responsibilities with Story Mediation and the CSC method. Not only is the Story Mediator responsible for 
re-telling the story while seeking validation of the crafted mirror material but he or she also needs to be attuned to the storyteller's complementary information to the mirror material (soon to be script).

Following this session, the mirror material is updated by the primary Story Mediator and shared (only) with the storyteller. The storyteller will then have the freedom to continue building on the mirror material to fully appropriate its content to become a personal "script." The "script" then can evolve and the storyteller can work independently on his/her "script" for a particular context and audience. The first opportunity to try out the script with Collaborative Storytelling in organisational change is during a workshop alongside work colleagues (other storytellers) and the Story Mediators.

To prepare for the workshop, Story Mediators meet after the validation sessions are complete to compare how the content of different mirror materials intersect. Commonalities among stories, such as metaphors, will be given special attention, as they will help to structure the workshop: defining the major themes and tailoring the activities for that particular community of practice.

\section{Part Three}

\section{Testing Scripts in a Workshop}

Although there are endless possibilities for tailoring the workshop in relation to time and the themes of many stories collected and validated, there are "traditional" ways to structure the event(s). In ideal scenarios, the organisation would be prepared to participate in a six-hour workshop divided into three metaphorical fields that reflect the work in the past, present, and future. These fields are called (1) Nurturing the Roots, (2) Occupational Well-being as part of a holistic story, and (3) Metaphorical Tourism.

\section{Nurturing the Roots}

The "Nuturing the Roots" metaphor aims to signify origins such as how the stories at work have become what they are, starting from individual stories and how their paths have merged at the organisation. The metaphor also aims to reconnect to the stories of how work used to be before the change. The aim of this metaphor is to acknowledge different sources, 
inform how the organisation's story affects individuals, and validate that each story, as the representation of one's experience, is worth being listened to. Those stories, a lot of the time, are foundational to the feelings towards collaboration for the purpose of change.

The metaphor of "roots" reminds the group that although hidden, stories are important and even more present than they realise. Nurturing those stories does not mean to keep bringing the "roots" up, instead there should be an opportunity to learn the reasons why the root stories sustain the collective sense of identity in the organisational context. Nurturing the stories of before (in relation to now) links back to the origins of the organisation, its founders, and the work that was needed in order for the organisation to be what it is. Ultimately, the meaning proposed by Nurturing the Roots leads back to people and their stories as individuals.

Story Mediators are responsible for facilitating the discussion in a way that the exchange of stories is well-balanced with a fair amount of time to all participants. There are some guidelines that frame the type of stories that could be shared in that context and for that audience.

Reflect and take notes on the following topics:

1. Your early story: background, personality, and interests

2. The path you have taken until now: choices, studies, career

3 . Your connection: what brought you here and how your story relates to this work

Story Mediators will give some time for the storytellers to think about the guidelines and craft a small script with the main topics that each individual would like to share.

Having gone through the two previous Story Mediation sessions (externalisation of stories and validation of stories), the storytellers can use the script that they had previously worked on to select the content that is appropriate for that workshop setting. There should be a time dedicated for each participant to be the storyteller and receive direct feedback from his or her peers.

While not telling a story, each participant should be an active listener ${ }^{3}$ to provide resourceful but authentic feedback. To help with that, we ask the participants to follow some guidelines: 
- How does your colleague's story relate to your story?

- What caught your attention in the story?

- Was there something significant that you didn't know about the person?

* Take notes and consider some words of encouragement.

With each storyteller's turn, there should be a round of feedback by the other storytellers. After the round of feedback, the storyteller can express his or her thoughts to the group regarding how his or her story had been received. In the meanwhile, Story Mediators can collect information that complements the overall themes, which later can be added to the final report.

\section{Occupational Well-Being as Part of a Holistic Story}

Our bodies and social identities experience work differently and uniquely. How we communicate and socially construct our physical and emotional needs as well as limitations are influenced by our social worlds and systems of narratives both inside and outside the workplace.

Describing physical and psychological needs at work can be difficult, especially as it can lead to vulnerable situations. To guide preparation for Collaborative Storytelling Activity, the Story Mediators introduce eight dimensions of experiencing wellness (e.g., Smith and Puczkó 2008 who describe six dimensions, p. 57) which are connected in a circle (see Fig. 5.3).

The storytellers are requested to rank these dimensions from top priority to least priority in relation to their lifestyle choices (Table 5.1). There are two ways that these dimensions can be ranked: (1) the current reality and (2) the ideal scenario. The current reality reveals which areas have been prioritised and which areas have been neglected. Whereas the ideal scenario informs what the preferences are in relation to a well-balanced and healthy lifestyle.

By ranking wellness dimensions, the storytellers get a chance to share their values and beliefs about their well-being, but also the stories that have influenced the choices in their lifestyle. For instance, in past workshops, storytellers passionately shared why one dimension means more 


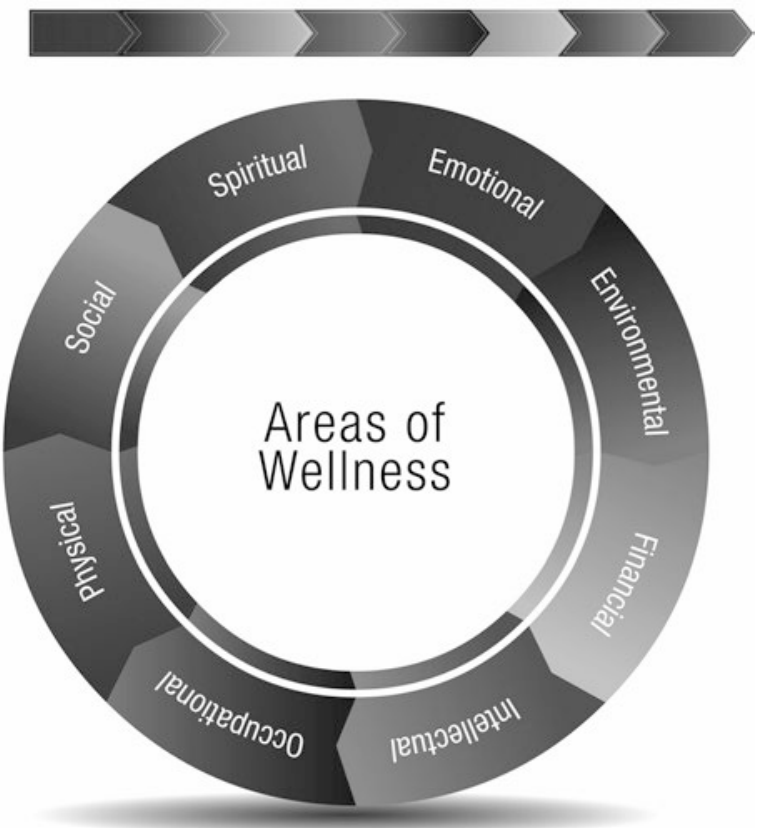

Fig. 5.3 The wellness dimensions: eight areas of physical and psychological wellness

than another, revealing a deeper understanding of how people socially and physically experience wellness in their lives. It also gives the storytellers an opportunity to explore their personal powers within their positions at work.

In May 2020, Tricia conducted a CSC workshop amongst multidisciplinary professional students of a master's in health business management. In relation to their work in the context of the global pandemic, COVID-19, the students ranked their wellness dimensions individually and then shared as a group.

The story exchange was lively to say the least. All 25 participants shared their rankings and described the reasons behind their list of wellness priorities. One conversation, in particular, revolved around 


\section{(continued)}

financial vs. spiritual dimensions, with one participant being unconvinced that finances should not be placed above all the other dimensions. He asked the group: "if one does not have material wealth, then how can the other dimensions be sustained?" Another participant replied that even when she did not have financial wealth, it was her sense of a bigger spiritual purpose that kept her feeling well and hopeful.

Table 5.1 General definitions of wellness dimensions in alphabetical order

\section{Emotional}

Awareness of one's feelings, what those feelings are associated with and how they can be expressed.

\section{Environmental}

Awareness of physical/natural surroundings and one's responsibility to care, maintain, or create an environment that enables a healthy/sustainable lifestyle.

\section{Financial}

Feeling satisfied with the current and future financial situation and having a sense of control and ownership over resources.

\section{Intellectual}

Stimulated mind and the desire to learn new concepts, to improve one's skills, to be mentally challenged, and seek accomplishment.

\section{Occupational}

A strong sense of working role and how this role is aligned with your calling, your values, your talents, and purpose.

\section{Physical}

Recognising and proactively maintaining biological needs related with good nutrition, activity, and sleep for the body to function well.

\section{Social}

Developing a sense of connection, belonging, and a well-established support system.

\section{Spiritual}

Being connected with a sense of meaning and expanding one's sense of purpose in life. Exercising wonderment and having a belief beyond one's own control.

\section{Metaphorical Tourism}

In this part of the workshop, the "tourism" metaphor taps into the meaning of "journey" but instead of giving a grand significance, such as "life's journey," it is used to signify the movement of ideas and stories about a reality that is not (currently) tangible. This Metaphor can be appropriated to different timelines.

What makes this a metaphorical tourism as opposed to a journey is that touristic trips are temporary. This reminds the "tourists" that they have a 
familiar place to come "home" to, meaning the current, non-imaginary reality, after exploring the new imaginary situation.

In the context of the workshop, it suggests a "visit" as to how the future could be. As mediators, we introduce Metaphorical Tourism as a follow up to build on the exchange that happened earlier in Nurturing the Roots. With that timing, Story Mediators propose an alternative meaning for the story exchanges. In addition to being root stories, we refer to previously "hidden" stories as stories that now have been "unpacked." In other words, unpacked stories suggest that the storytellers know more about one another because they shared some of the stories that they had been carrying in their personal backpack. Now, it comes the time to work together with a shared luggage, where the challenge is to choose where they want to go and what type of stories should be taken to the destination they will visit.

The destination represents the change, not as an unpleasant place to consider but just as a touristic destination (that one chooses willingly). Change, in this context, represents the ideal scenario. Perhaps, some of the tourists are more experienced than others, meaning that they know exactly how the ideal scenario should look like because they have visited the destination many times before, metaphorically. While other tourists have yet to conceptualise what the ideal scenario should look like.

In the "metaphorical trip," the Story Mediators serve as "tourist agents," and the storytellers prepare themselves for a collective trip towards an ideal future destination. To illustrate the activity, we suggest a single metaphorical luggage for group travel. The Story Mediators then facilitate the story exchange as to what stories could be brought along, and what should be left behind to avoid extra weight for the type of destination.

Packing the luggage together allows participants to express their interpretation of the future collective destination of the work activities, and what material objects (e.g., tools) and expectations (written or unwritten) should be brought along for the journey. With this process, new or reinvented tools and strategies of the work itself can emerge through interpretations of the metaphor (of the ideal destination) and the previous story exchanges.

Based on the model of Collaborative Storytelling Activity System (Fig. 3.2), the Story Mediator facilitates the discussion of packing the luggage by asking the storytellers to think about the following questions in relation to the work activities: 
- What is your role at work and what do you need to fulfil that role?

- What is your destination/where do you want to get to?

- Who are you travelling with?

- How should the responsibilities be divided?

- The map: what type of rules and guidelines should be put into place?

- What type of tools or resources do you need?

- Who is part of your community? Think about the landscape that surrounds the journey.

Through packing the luggage, the Story Mediator helps the group identify commonalities, in the face of disagreements, towards a potential "compromising zone." This compromising zone is documented by the Story Mediators through the agreement of the group and the potential areas of development. This document is later presented to the group as a new material story based on the entirety of the CSC intervention.

\section{An example of Metaphorical Tourism}

In 2019, we conducted a one-day workshop with a gender equality consultancy who recently received external funding for a two-year project. The consultancy was credible with a strong reputation of past work on issues of gender equality at the workplace and within national policymaking. The external funding expanded the consultancy from the founder to a team of six individuals: three researchers, a project manager, and a social activist for LGBT+ rights. We were asked to facilitate the CSC workshop because the founder wanted to start the project as a team with clear expectations of the project purpose, objectives, and members' roles.

By exchanging stories in relation to the project, there were various commonalities in the stories that emerged such as higher education degrees in gender studies; searching for the "right path"; questioning the sense of purpose and financial stability through work; combining work with activism and equality values; and seeing their career paths as a "calling." 
(continued)

During the Metaphorical Tourism, with the support of the Story Meditators, the group identified that the consultancy is a platform for all of them and represents a larger community of activists that should be acknowledged and included. Within this "compromising zone" identified as the destination, rules were established on how to get there. Those rules included:

- The consultancy should not be limited to the founder. Instead, the consultancy is a place where team members can work on common projects, but also exchange experiences and feel that they belong to a community.

- As a platform, the consultancy is a collection of combined skills that should be considered when designing new solutions or seeking out new projects. With that mindset, the work and the sense of purpose can be extended to a wider network/timeframe.

- As a community, the people working with the consultancy should consider promoting each other's work and career aspirations by valuing their areas of expertise as well as their interests and choices.

- As a community and a platform, the consultancy should be used as a reference point to connect people and generate new opportunities for the future.

The guidelines of the journey became:

- To be aware of what type of knowledge can be found within the consultancy's community, and how such knowledge contributes in practice to the work and benefits the community it serves. It should also consider different perspectives of gender research with a holistic view of what equality is.

- To clarify the methods: by knowing what the consultancy's community can offer regarding tools and skills. As a result, the team should craft a clear message and speak louder in all the "communities" or platforms that they also belong to.

- To consider the tone of communication and avoid criticism: how to tell the consultancy's story. The message should consider the audience that the consultancy is aiming at, who else they might be reaching, and the channels of distribution. Depending on those elements, the message must be crafted in a way that matches the audience's "language," allowing the story to be interpreted properly. 


\section{Sensing the Change by Drawing the Destination}

Within Metaphorical Tourism, storytellers craft the common metaphor of the destination through a drawing activity. With this activity, the storytellers are provided blank sheets of paper and coloured pencils. Once equipped, the Story Mediators instruct the storytellers to draw an image of the ideal destination and to position themselves with their community of practice as fellow travellers.

This drawing exercise requires the participants to gather in a circle. Once the storytellers begin to interpret their understanding by drawing, we ask the storytellers to pass their unfinished drawing to their neighbour to continue the interpretation. Each storyteller is then instructed to continue someone else's creation by adding their interpretation to the drawing.

This request of letting go of one's drawing not only surprises the storytellers but also puts into perspective that a craft mindset should also be prepared for unpredictability. Passing the drawing around gives others a chance to craft the same artefact collectively.

Once each drawing is passed to all the storytellers, the original drawing is returned to the one who started it. The storytellers then have an opportunity to exchange stories as to what they intended to draw at first and how they interpreted the collaborative outcome of the drawing.

The storytellers' interpretation considers their role in the community of practice and the significance of the change as a metaphorical destination.

Although talking is helpful in collective sensemaking, exploring alternative ways of expression (e.g., through art) can deepen imaginary possibilities leading to creative solutions. With a work as craft mindset, storytellers use their senses to communicate their interpretation of the future destination of the work based on their imagination and embodied lived experiences. The embodied lived experience is associated with a common metaphor (change as destination and/or any other metaphor that emerged in the previous CSC phases).

Like craftwork, testing out our individual scripts and applying a common metaphor to the work present opportunities to learn. Drawing the 
ideal destination fosters the imagination to better understand how the scripts and metaphors as new tools can help do the work better together. In other words, in times of change, using the crafted scripts and a metaphor serves as a catalyst to imagine what future work could be like as a community of practice.

With a work as craft mindset, testing out the new scripts and metaphors most often begins with frustration or "breaking the mold of fit-for-purpose" (Sennett 2008, p. 210). And yet, this frustration has rich potential of "telling yourself something you know can be other than you assumed" (Sennett 2008, p. 11), and the humility of "coming-to-grips" that unresolved issues of the tool and work may remain unresolved (Sennett 2008, p. 154).

In some workshops, because of time limitations, the drawings are completed solely by the storyteller, who later shares their interpretation with the group. Below are two pictures of a CSC workshop based on the interpretation of a digital platform called the Health Village (as the metaphorical destination).

The first drawing was created by a former patient who was asked to serve as an expert member in building the Health Village. He interpreted his experiences without the digital platform, and his subsequent work contribution to the Health Village.

The person with an arrow in the head represents himself when he had a stroke. The maze represents the physical pain of rehabilitation as well as the emotional pain of getting information on how to heal from the stroke. The bike on the other side of the maze represents a return to "normal" or gaining strength to do previous activities before the stroke. The former patient communicated that to get to the bike, there should be more teamwork within the group to acknowledge individual efforts. The Health Village destination for him was not only about the functionality of the digital tool but a state-of-mind of feeling supported, equipped, trusted, and autonomous to get to the other side where his bike was waiting for him.

The second image from the CSC workshop was done as a pair, which was a request of the two storytellers. One of the storytellers was a neurologist and the other, a nurse. In this picture, they described the Health Village as something "positive," where practitioners are hard at work, and those who come to the village are welcomed and joyful. As the neurologist expressed 
herself: "We hope to bring health and, in this sense, the name [Health Village] has a positive echo" (workshop notes, 3.5.2019) (Fig. 5.5).

Differing from the picture in Fig. 5.4, the metaphor and the tool is contributing to a community of practitioners who are serving the village. The nurse and neurologists are working on the roof, while others benefit from their skills, motivation, and teamwork.

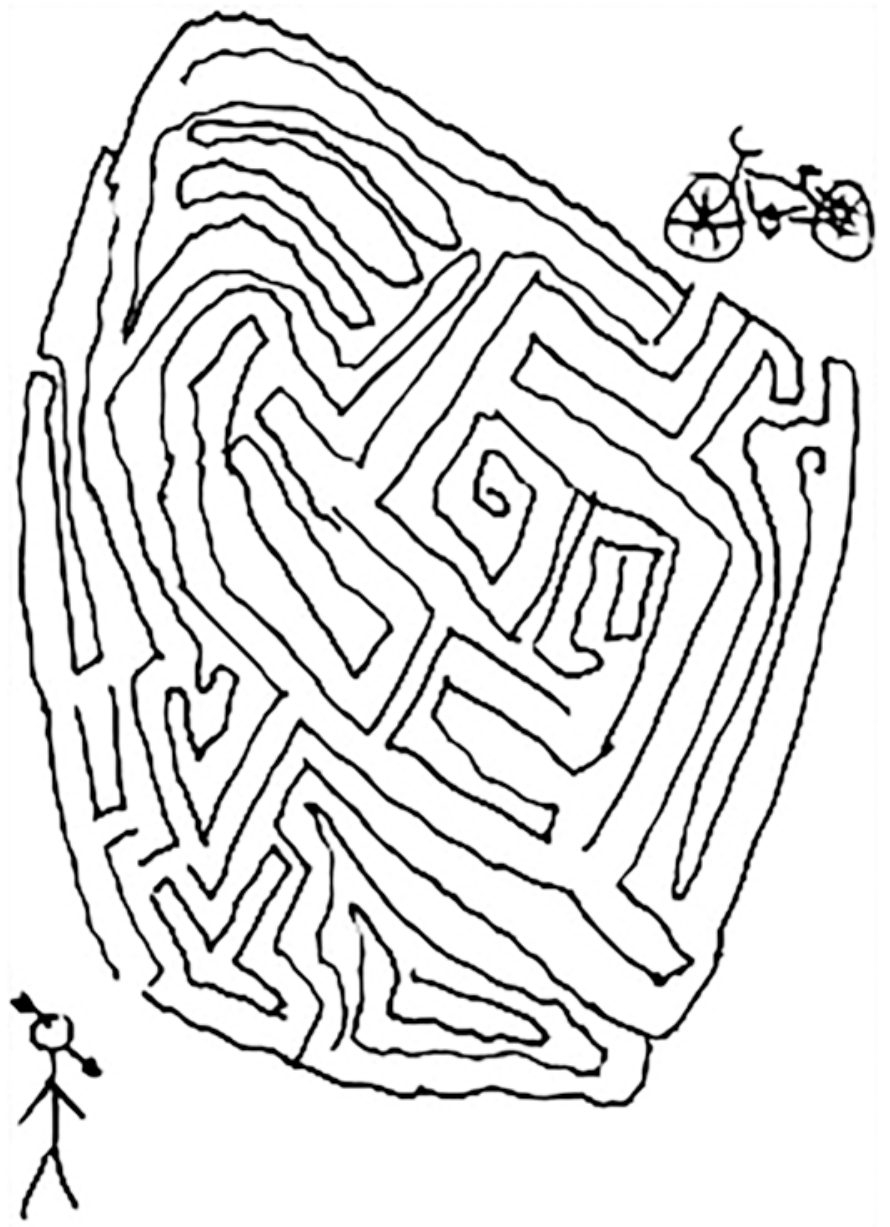

Fig. 5.4 An example of a metaphoric field interpretation 


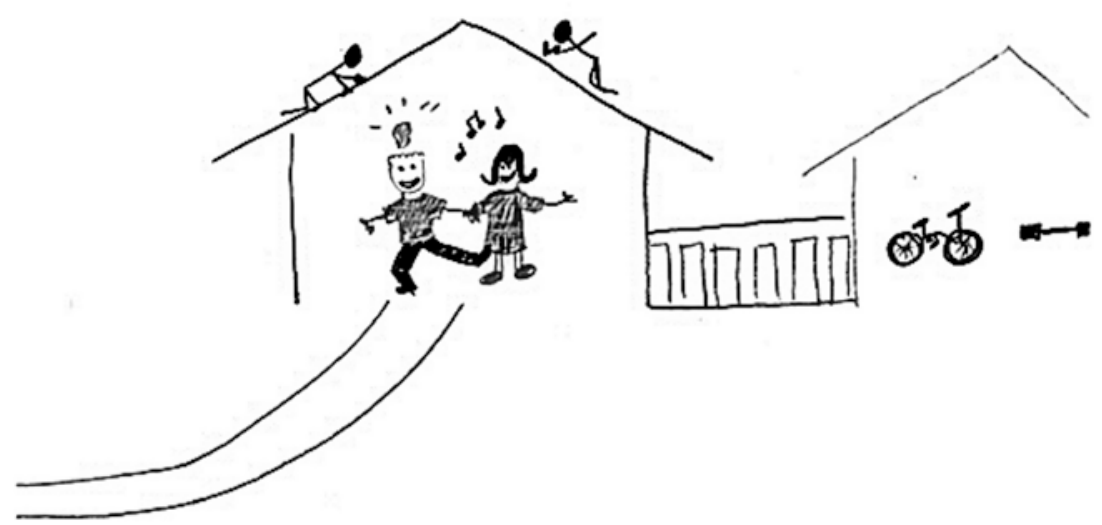

Fig. 5.5 An example of health care practitioners' interpretation of a metaphoric field

\section{PART Four}

\section{The Material Story: Updating Scripts and the Report}

From the initial contact with the workplace to the last moments together in the workshop, the Story Mediator takes detailed memos and notes, and through each stage, offloads these interpretations onto another Story Mediator.

In most respects, CSC has an ethnographic approach to research; however, it is developed from the original practice, which used video and audio recordings of all sessions and subsequent transcriptions. The original practice was influenced by traditional qualitative methods, and yet, in practice, storytellers gave feedback that recording took away from the intimacy of sharing with the Story Meditator.

With a work as craft mindset, we have decided that the practice of attentively listening, observing, and being present for the storyteller should be symbolically and materially respected with the sole use of a pad of paper and a pen. This allows the Story Mediator to listen but also embody their senses holistically in the workplace context. 
Documenting the Collaborative Story Craft process is important for legitimacy and reliability of the tools, but also to hold the Story Mediators and the storytellers accountable.

In addition to the compromising zones and the areas of potential development witnessed in the workshop, documenting also adds another layer of validation to the exchange, ensuring that decision makers, as well as other contributors of the organisational change, can hold each other accountable going forward towards a common "destination."

"Gaslighting" is entrenched in power structures, and as organisational change in the workplace is initiated by the sense-giving of people in powerful positions, it is vital that the collective sensemaking process of Collaborative Storytelling is documented.

Gaslighting, a term now commonly used in various workplace contexts (e.g., for women of colour scientists, Rodrigues et al. 2021; in nurse academia, Christensen and Evans-Murray 2021), is understood as a form of psychological manipulation that aims to provoke self-doubt in the targeted individual or member of a targeted group, making the individual and/or group members question their own memory, perception, and sanity.

Gaslighting in the workplace can occur when individuals perform actions that cause colleagues to question themselves and their actions in a way that is detrimental to their careers (Adkins 2019).

The report serves as a material artefact that the process occurred, there was an effort to achieve purposeful consent, and that each member could share their lived experiences. As written by Hannah Ardent (1968, p. 105) in her book Men in Dark Times about twentieth century author Karen Christentze Dinesen, who wrote under the male pen name of Isak Dinesen:

It is true that storytelling reveals meaning without committing the error of defining it, that it brings about consent and reconciliation with things as they really are, and that we may even trust it to contain eventually by implication that last word which we expect from "day of judgement." And yet, if we listen to Isak Dinesen's "philosophy" of storytelling and think of her life in the light of it, we cannot help becoming aware of how the slightest misunderstanding, the slightest shift of emphasis in the wrong direction, will inevitably ruin everything. 
In light of Ardent's writing, the material story is not fixed, as it is everevolving and changing to different times and contexts. With a material story, there is possibility for growth, expansion, and continuous questioning of what is truth and purpose at the workplace. As Martin Luther King Jr. spoke in his 1968 speech: "Power properly understood is nothing but the ability to achieve purpose. It is the strength required to bring about social, political and economic change."

As storytellers, each participant of the CSC intervention possesses a crafted script that can be used for their chosen audience in the future.

After the CSC workshop, the entire documented process is materialised by the Story Mediators within three weeks following the last session of CSC. This document is sent to the individuals in positions of power as a material artefact of Collaborative Storytelling, representing a sensemaking process activity in organisational change. The document has the potential to garner consent, legitimacy, and inclusion to future sense-giving processes of change.

\section{Conclusions}

Collaborative Story Craft intervention initiates a process of awareness. This process not only calls attention to the hidden power of stories during organisational change but it also reveals how different individuals experience change through their embodied senses, taking into account the social worlds that they come from. Through CSC, it is possible to explore the hidden stories and understand how they influence our judgments or even govern our decisions.

Although the work with members of the organisation and their stories initiates with CSC, building narratives for collaboration in times of change can continue beyond the intervention, if Collaborative Storytelling Activity (CSA) is incorporated into organisational practices.

Through Story Mediation, acknowledging members of the organisation as storytellers and including their voices can enable everyone involved to communicate more effectively during new cycles of the organisation's story. Investing in Story Mediation training directed at practitioners that belong to the community of practice would ensure that the work as craft mindset can be used systematically for collaboration. In that sense, consulting with external Story Mediators would be a possibility but not a requirement. In our view, this would be a sustainable approach to build on the organisation's narratives during times of change and beyond. 


\section{Notes}

1. This paradoxical realisation (of the Story Mediator having an audience), also acknowledges him/her as a storyteller and therefore as a contributor in the Collaborative Storytelling Activity of the organisation. Although Story Mediators are collaborators during the Collaborative Story Craft process, they do not seek credit in the public story, which is told by the members of the organisation.

2. We found that the circular model is a more accessible version for organisational members and easier to understand.

3. See Anderson and Jack (1998) for "learning to listen"; see Fromm (1998) for "the art of listening."

\section{REFERENCES}

Adkins, Karen C. 2019. Gaslighting by crowd. Social Philosophy Today 35: 75-87. Anderson, Kathryn, and Dana C. Jack. 1998. Learning to listen: Interview techniques and analyses. In The oral history reader, ed. Robert Perks and Alistair Thomson. New York: Routledge.

Arendt, Hannah. 1968. Men in dark times. Florida: Houghton Mifflin Harcourt. Christensen, Martin, and Anne Evans-Murray. 2021. Gaslighting in nursing academia: A new or established covert form of bullying? Nursing Forum 56: 640-647.

Cleland Silva, T., and Paulo de Tarso Fonseca Silva. 2019. Validating change through collaborative story craft. In SAGE research methods cases part 2 (SAGE research methods cases). Thousand Oaks: SAGE. https://doi.org/10.4135/ 9781526478245.

Cleland Silva, Tricia, and Paulo de Tarso Fonseca Silva. 2021. Collaborative Story Craft as a tool for inclusive workplace practices. In History and storytelling in business, ed. Albert Mills, Nick Deal, and David Boje. Singapore: World Scientific.

Fine, Gary Alan. 2003. Crafting authenticity: The validation of identity in selftaught art. Theory and Society 32: 153-180.

Fromm, Eric. 1998. The art of listening. New York: Continuum.

Jasanoff, Sheila. 2015. One. Future imperfect: Science, technology, and the imagination of modernity. In Dreamscapes of modernity, ed. Shelia Jasanoff and SangHyun Kim, 1-33. Chicago: Chicago University Press.

Luckman, Susan. 2015. Craft and the creative economy. Switzerland: Springer.

Rodrigues, Michelle A., Ruby Mendenhall, and Kathryn B.H. Clancy. 2021. "There's realizing, and then there's realizing": How social support can counter 
gaslighting of women of color scientists. Journal of Women and Minorities in Science and Engineering 27 (2): 1-23.

Sennett, Richard. 2008. The craftsman. London: Penguin.

Smith, Melanie, and László Puczkó. 2008. Health and wellness tourism. New York: Routledge.

Open Access This chapter is licensed under the terms of the Creative Commons Attribution 4.0 International License (http://creativecommons.org/licenses/ by $/ 4.0 /$ ), which permits use, sharing, adaptation, distribution and reproduction in any medium or format, as long as you give appropriate credit to the original author(s) and the source, provide a link to the Creative Commons licence and indicate if changes were made.

The images or other third party material in this chapter are included in the chapter's Creative Commons licence, unless indicated otherwise in a credit line to the material. If material is not included in the chapter's Creative Commons licence and your intended use is not permitted by statutory regulation or exceeds the permitted use, you will need to obtain permission directly from the copyright holder.

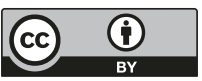

